\title{
Exotismo e Irracionalidade: ${ }^{1}$
}

\section{as narrativas da imprensa francesa sobre a seleção brasileira de futebol nas Copas do Mundo de 1958 e 1998}

\section{Exoticism and Irrationality:}

\section{French media narratives about the Brazil national football team in the World Cups of 1958 and 1998.}

Ronaldo Helal

Doutor em Sociologia pela New York University e professor titular da UERJ. Universidade do Estado do Rio de Janeiro, Departamento de Comunicação, Rio de Janeiro (RJ), Brasil.

Introdução

Para José Carlos Rodrigues, autor de "O Rei e o Rito", um dos artigos fundacionais do campo

O objetivo deste artigo é apresentar os resultados parciais de uma pesquisa realizada na Biblioteca Nacional da França entre junho e agosto de 2017, sob a supervisão de Patrick Mignon, do Institut National du Sport, L'Expertise et de la Performance - INSEP. Parte-se da hipótese de que foi a partir da atuação da seleção brasileira na Copa do Mundo da França, em 1938, e do "olhar" da imprensa francesa sobre o futebol brasileiro que as ideias do antropólogo Gilberto Freyre e do jornalista Mario Filho, de que o futebol brasileiro seria mais artístico, se consolidaram no país. Pressupõe-se que os franceses olhavam o Brasil

\footnotetext{
1 Uma versão preliminar e em espanhol desse artigo foi apresentada no congresso da Latin American Studies Association, realizado em Barcelona, em 2018. Depois, outra versão, também em espanhol, foi publicada na revista Lúdicamente, volume 8 , número 15, 2019.
} 


\section{ALCEU}

ISSN: 2175-7402

como um país exótico, com todos os estereótipos "positivos" e "negativos" que permeiam essa visão. Esses estereótipos continuariam aparecendo na imprensa francesa na Copa do Mundo de 1958? E eles poderiam ser mantidos na Copa do Mundo da França, em 1998?

O artigo apresenta uma análise das narrativas do jornal L'Équipe sobre o futebol brasileiro nas Copas de 1958 e 1998. Essas são duas Copas do Mundo emblemáticas. Em 1958, o Brasil foi campeão pela primeira vez e derrotou a seleção francesa nas semifinais por 5 a 2. Em 1998, Brasil e França chegaram à final, e a França venceu o Brasil por 3 a 0, na Copa do Mundo em que foi anfitriã.

\section{Um pouco de história sobre o assunto}

Durante a Copa do Mundo de 1938, Gilberto Freyre publicou no jornal Diário de Pernambuco um artigo intitulado "Foot-ball Mulato", que se tornou um marco na literatura sobre o futebol brasileiro quando se trata de falar sobre o suposto estilo de jogo do Brasil2. Nesse artigo, Freyre elogia os "atributos" dos "afro-brasileiros", seguindo raciocínios semelhantes aos que escreveu em seu clássico livro CasaGrande e Senzala ${ }^{3}$.

Suspeitamos que a base simbólica do futebol brasileiro tenha suas origens na Copa de 1938, a partir de uma série de fatores inter-relacionados: a) as repercussões do artigo de Freyre; b) as crônicas do jornalista Mario Filho na imprensa esportiva; e c) o olhar dos franceses sobre o futebol brasileiro, que, por sua vez, daria origem às ideias de Freyre e Filho ${ }^{4}$. Sobre este último fator, temos evidências de que o olhar francês oscilava entre a admiração pelas habilidades dos jogadores daquela equipe de 1938 e uma crítica a um suposto primitivismo. José Sérgio Leite Lopes (1999, p. 74) cita, por exemplo, um artigo do jornalista

\footnotetext{
${ }^{2}$ Ver, por exemplo, Maranhão (2006) e Barreto (2004).

${ }^{3}$ Ver, a respeito, Araújo (1994).

${ }^{4}$ Desde meados do século XIX, a influência francesa é notável em um Brasil que buscava construir sua imagem enquanto nação. Destaca-se a missão artística francesa instaurada no Brasil, em 1816, com o objetivo de promover o ensino das artes plásticas no país. O olhar francês foi fundamental para o Romantismo, um dos mais importantes movimentos literários na história do Brasil. Em grande medida, é a partir do olhar francês que, no Romantismo, "os brasileiros puderam sentir como o particularismo, inclusive sob a forma do pitoresco, se ajustava ao desejo de diferenciação e busca de identidade nacional" (CANDIDO, 2004, p. 19). Sou grato a Leda Costa por essas observações.
} 
Gabriel Hanot ${ }^{5}$, publicado no jornal Le Mirroir des Sports após a derrota do Brasil para a Itália na Copa do Mundo de 1938, no qual Hanot afirma que:

Os brasileiros, em sua maioria com rostos morenos e sangue mestiço de ascendência negra, têm qualidades naturais maravilhosas que os tornam futebolistas natos. Infelizmente, a ideia de que o futebol é um esporte coletivo ainda não atingiu seus cérebros... Não peça para eles recorrerem aos recursos da inteligência para ajudá-los com suas proezas atléticas naturais e seus novos músculos. Não exija deles as qualidades que são esperadas de indivíduos sociais que vivem em sociedade ${ }^{6}$ (LEITE LOPES, 1999, p. 74, grifos nossos).

Afinal, quais eram as narrativas da imprensa francesa sobre o futebol brasileiro? Em investigação realizada nos jornais Le Petit Parisien e Paris Soir no período da Copa do Mundo de 1938, Arlei Damo (2007, p. 9) nos mostra que o “predicado da 'arte/artístico', atribuído ao estilo brasileiro, está impregnado de ambivalências, por vezes tidas como sinônimo de atraso na forma de jogar e, por extensão, de pensar dos europeus". Damo mostra que as narrativas oscilavam entre elogios às supostas características "artísticas" e críticas à “individualidade, prevalecendo sobre o trabalho em equipe" (DAMO, 2007, p. 5)

Curiosamente, Gilberto Freyre, em seu artigo "Foot-ball Mulato", começa dizendo que estava respondendo a um jornalista que queria saber o que ele pensava sobre "a admirável atuação brasileira nos campos de Estrasburgo e Bordeaux". Nesse caso, o jornalista não identificado estaria elogiando as atuações da seleção, sem comentários críticos. A partir daí, Freyre descreve as qualidades de nossos atletas afro-brasileiros para explicar o sucesso daquela equipe, que terminou a Copa em terceiro lugar. Freyre elogia a miscigenação racial e afirma que havia sido fundado um estilo de jogo típico do Brasil: "uma dança dionisíaca", que algum tempo depois ficou conhecida como "futebol arte" ou "jogo bonito"7.

Tanto em Casa-Grande e Senzala quanto em "Foot-ball Mulato", a miscigenação racial seria fruto de uma norma harmoniosa que formava a população brasileira. De alguma forma, as teorias sociológicas

\footnotetext{
${ }^{5}$ Gabriel Hanot foi um dos nomes mais influentes para o desenvolvimento do futebol europeu. Dentre os seus legados, está a concepção de um torneio europeu de clubes - a Taça dos Campeões Europeus (atual Liga dos Campeões da Europa) - e de um dos maiores prêmios individuais do esporte - a Bola de Ouro -, premiação concedida pela revista France Football ao melhor jogador de futebol do ano. Importante salientar que, antes de se tornar jornalista, Hanot foi jogador e treinador de futebol. Fonte: <https://maisfutebol.iol.pt/soldados-desconhecidos/rubrica/o-homem-que-via-mais-longe-do-que-os-outros>. Acesso em: 20 fev. 2021.

6 Essas e as demais citações a jornalistas, jornais franceses e acadêmicos foram traduzidas livremente por mim. Por contingenciamento de espaço, não irei reproduzi-los aqui.

${ }^{7}$ Dentro e fora do país. A imprensa argentina, em geral, define o futebol brasileiro como “jogo bonito". Ver Helal (2007).
} 
do país estavam de acordo com o projeto nacionalista do presidente Getúlio Vargas ${ }^{8}$. E seus conceitos eram miscigenação e integração.

O "país do futebol" teria sido uma "construção" social apoiada por jornalistas e intelectuais em um momento de consolidação do "Estado-nação", seguida de formulações acadêmicas sobre a sociedade. Se, antes, pelas lentes de acadêmicos como Oliveira Viana e Nina Rodrigues ${ }^{9}$, a miscigenação racial era vista como uma explicação para o "atraso" do país, a partir de Casa-Grande e Senzala, a miscigenação começa a ser entendida como um valor positivo e uma força da população brasileira.

Dentro do projeto nacionalista do Estado Novo, essa forma de entender a cultura se consolida no país. Nesse sentido, o jornalista Mario Filho foi fundamental na utilização do futebol como meio de "construir" uma ideia de nação brasileira. Filho chegou a ter proximidade com Gilberto Freyre, que prefaciou sua obra mais conhecida, $O$ negro no futebol brasileiro, em que a união do futebol com a nação fica mais evidente ${ }^{10}$.

A ideia de que o Brasil seria o "país do futebol" e de que a seleção nacional seria a "pátria de chuteiras" - alcunha do dramaturgo e escritor esportivo Nelson Rodrigues, irmão de Mario Filho - se consolidou entre os anos 1950 e 1970, período em que o Brasil conquistou um vice-campeonato - em 1950 - e um tricampeonato - 1958, 1962 e 1970.

Os franceses teriam mudado sua maneira de ver o futebol brasileiro depois de 1938? Afinal, como os franceses nos olham? Como donos do "jogo bonito" ou como "primitivos", faltando um "jogo coletivo"? O que isso pode nos dizer sobre a relação entre os dois países?

\section{Brasil e França na Copa do Mundo de 1958}

A Copa do Mundo de 1958 foi disputada na Suécia entre os dias 10 e 29 de junho daquele ano. A seleção brasileira conquistou sua primeira Copa do Mundo ao derrotar os anfitriões por 5 a 2. Antes dessa

\footnotetext{
${ }^{8}$ Sobre esse projeto nacionalista e o esporte no período, ver Souza (2008) e Drumond (2014).

${ }^{9}$ Ver, por exemplo, Nina Rodrigues, As raças humana e a responsabilidade penal no Brasil (1894) e Oliveira Viana, Populações Meridionais do Brasil (1920)

${ }^{10}$ Para o debate sobre a importância do livro O Negro no Futebol Brasileiro como fonte histórica, ver os artigos contidos no livro A Invenção do País do Futebol: Média, Raça e idolatria, de Ronaldo Helal, Antonio Jorge Gonçalves Soares e Hugo Lovisolo (2007).
} 


\section{ALCEU}

ISSN: $2175-7402$

partida, a seleção derrotou a França também por 5 a 2. Concordamos com Leite Lopes (2004, p. 25) quando afirma que "o estilo brasileiro só pôde se firmar internacionalmente e também internamente após a vitória na Copa do Mundo de 1958, na Suécia”. Depois do terceiro lugar em 1938 e do vice-campeonato em 1950 (não houve Copas do Mundo em 1942 e 1946 devido à Segunda Guerra Mundial), a seleção brasileira finalmente venceria a competição.

No dia 10 de junho, uma reportagem assinada por Fernand Albaret elogiou a força atlética e a técnica do Brasil. "Excelente condição física (...) Eles são técnicos extraordinários e sua condição física é incrível". A matéria também elogiou o meio-campista Didi e registrou que a imprensa brasileira pedia Garrincha no time, na ponta direita.

No dia 12 de junho, após a partida contra a Inglaterra, que terminou empatada ( 0 a 0 ), o jornal disse que o Brasil mostrou suas qualidades incomparáveis no primeiro tempo. Ao mesmo tempo, a nota dizia que a seleção brasileira, assim como a argentina, não teria tido resistência física: "Eles mostraram ontem. O defeito de sua armadura, que é a de todos os sul-americanos. Eles não aparecem mais como super-favoritos" (L'ÉQUIPE, 12/06/1958, grifo nosso).

O que chama a atenção nessas matérias é a ênfase, ainda que contraditória, na preparação física, bem como uma visão geral e estereotipada dos sul-americanos, como se todos nesse continente tivessem os mesmos "defeitos naturais".

No entanto, junto com a questão física, a ideia do jogo bonito também começa a aparecer. O jornalista Gabriel Hanot, o mesmo que mencionamos no início, escreve na capa do jornal que "A graça brasileira contrasta com a força britânica". Tanto a questão física quanto a que fala de habilidades técnicas são, de certa forma, semelhantes às que surgiram nas análises feitas por Damo e Leite Lopes sobre a Copa de 1938. Ambas são retratadas como sendo parte da "natureza" dos brasileiros.

Depois da partida contra a União Soviética, que o Brasil venceu por 2 a 0, o jornal, no dia 16 de junho, colocou no título: "Vinte minutos de fogos de artifício com Garrincha, Didi, Vavá e Pelé". E, no dia seguinte, uma matéria intitulada: “'Torto', genial, grande inventor dos dribles, o homem que em breve terá uma estação de trem pessoal: Garrincha, o melhor ponta direita que já vi"11. A matéria é de Gabriel Hanot,

\footnotetext{
${ }^{11}$ A expressão "ter uma estação de trem pessoal" ou "sua própria estação de trem" pode ser uma referência ao fato de que Garrincha costumava ir de trem para sua cidade natal. Ver Mostaro (2012) e Castro (1995).
} 
com uma foto de Garrincha deitado na grama com roupas de treino. A frase é atribuída ao treinador da então URSS, que teria dito: "Nunca vi um jogador de futebol desta classe". Na primeira página do jornal, uma foto de Garrincha driblando um defensor, camisa 3, e o título: "Brasil tem um ponta direita extraordinário".

Curiosamente, um dia após a seleção brasileira ter vencido o País de Gales por um placar apertado de 1 a 0, o próprio Hanot diz que faltava ao time “jogo coletivo" (L'ÉQUIPE, 20/06/1958). Em outras palavras, quando a equipe vence e "joga bonito", temos uma narrativa que valoriza as qualidades individuais. Porém, quando a equipe não realiza o que supostamente se esperava de seu "estilo", observamos uma crítica do ponto de vista da razão: a falta de jogo coletivo. Em ambos os casos, se trabalha com atributos de ordem da natureza, confirmando a ambivalência observada por Damo (2007).

Essa ambiguidade se torna mais evidente antes da semifinal contra a França em 24 de junho. $\mathrm{Na}$ véspera, o L'Équipe apresenta uma entrevista com o ex-jogador francês Jean Snella, que trabalhava como assistente técnico da seleção francesa. A manchete: “Não perca o controle na frente de Garrincha!". A matéria enfatiza que Snella teria dito que o ponta direita "não faz nada com os outros de sua equipe, que joga de acordo com sua inspiração sem levar em conta os companheiros e que muitas vezes seus dribles não são objetivos" (grifos nossos). Há uma foto de Garrincha com a legenda: “Manoel Francisco 'Garrincha' [...] tem todas as qualidades individuais possíveis: flexibilidade, largada, velocidade, técnica. Mas, Snella disse, ele ainda não é um jogador de equipe. Essa é uma oportunidade para a seleção francesa" (L'ÉQUIPE, 24/06/1958, grifo nosso).

Na mesma nota, há uma entrevista com o treinador da seleção francesa, Albert Batteux, na qual ele declara que todos os adversários que a França tinha enfrentado eram conhecidos, por já terem jogado contra eles, além do fato de Snella ter trazido as informações dos adversários. Em seguida, afirmou que "os brasileiros, por outro lado, se eles têm uma característica, é a de não ter! Eles jogam de forma instintiva, devido às qualidades físicas extraordinárias" (L'ÉQUIPE, 24/06/1958, grifos nossos).

As duas entrevistas reforçam a dicotomia. Por um lado, o elogio às supostas qualidades individuais "instintivas". Por outro, as críticas à suposta falta de razão (jogo coletivo). Com a vitória do Brasil por 5 a 2 e a consequente classificação da seleção para a final, o jornal é todo elogio à seleção brasileira e a seus 
jogadores, não deixando espaço para a narrativa da "ausência de razão", prevalecendo a beleza do jogo da equipe e as qualidades técnicas dos jogadores.

No dia 26 de junho, o jornal francês apresenta mais uma entrevista com Albert Batteux. Quando questionado sobre que lições a França pode tirar da partida com o Brasil, o treinador responde: "Lições muito relativas, porque é verdade que nunca poderemos jogar como o Brasil, e todos os europeus estão no nosso caso [...] Quando jogamos contra os brasileiros estamos na presença de fenômenos, com tudo o que isso quer significar de coisas imprevisíveis" (L'ÉQUIPE, 26/06/1958, grifos nossos). Ainda nesse 26 de junho, o jornal apresenta nota assinada por Jacques de Ryswick com a manchete: "Os franceses são jogadores de futebol, os brasileiros saem de outro molde".

Ambos os elogios vêm da mesma fonte: a natureza do brasileiro, que seria imprevisível. A imprevisibilidade é, neste caso, positiva. A questão que se pode levantar é: gostaríamos de ter no universo da ciência e da política indivíduos imprevisíveis? Ou nesses universos os requisitos se voltam mais para a razão e a disciplina?

As críticas à suposta falta de razão, ou equilíbrio emocional, reaparecem no dia 28 de junho, um dia antes da final contra a seleção sueca, anfitriã daquela Copa. E, mais uma vez, a análise é do jornalista Gabriel Hanot. A matéria "Se os nervos do Brasil forem levados ao fim" pontua que que "apenas um perigo pesa sobre eles na hora da verdade: sua juventude de civilização e, consequentemente, sua fragilidade moral" (L'ÉQUIPE, 28/06/1958, grifo nosso). Mas ele diz que a fragilidade ${ }^{12}$ não apareceu contra os soviéticos ou contra os franceses, depois de levar o primeiro gol (quando Fontaine empatou em 1 a 1). E continua assim:

Dois valores supremos: 1) O desejo de completar o virtuosismo individual por meio de uma conduta racional dos movimentos dos grupos. 2) Sob a influência do Dr. Hilton Gosling e do professor de psicologia (ou melhor, do psicotécnico) João Carvalhais, o domínio total dos nervos em organismos que queimam internamente com o fogo tropical (L'ÉQUIPE, 28/06/1958, grifo nosso).

Observemos que Hanot imputa ao médico e ao psicólogo a responsabilidade pelo que seria o "aspecto racional" da equipe. Seria algo como atribuir a dois médicos (diplomados) o controle de instintos primitivos que seriam intrínsecos à região dos trópicos. O determinismo geográfico é evidente aqui.

\footnotetext{
${ }^{12}$ Aqui no Brasil o dramaturgo e cronista esportivo Nelson Rodrigues tinha criado a expressão "complexo de vira-lata", após a derrota da seleção brasileira na final contra o Uruguai em 1950. A expressão dizia respeito a uma suposta subalternidade dos brasileiros em relação ao que é estrangeiro, como se fosse um etnocentrismo invertido (RODRIGUES, 1989), o que nos leva à suspeita que essa narrativa na imprensa francesa, que fala de uma suposta "fragilidade moral", encontrava eco no Brasil.
} 
Com a seleção brasileira campeã, depois de ter derrotado a Suécia por 5 a 2 na final, o jornal elogia a organização defensiva do time, o que poderíamos interpretar como um olhar que coloca o Brasil no papel de times mais "racionais", ainda que jogando ofensivamente ${ }^{13}$. E, uma vez mais, Hanot elogia Garrincha: “Um ponta direita como Garrincha não existe e não é concebível na Europa” (L'ÉQUIPE, 30/06/1958). Mas ele não explica por que um "Garrincha" não seria concebível na Europa. Seria porque ele era um jogador dos trópicos?

Resumindo, podemos dizer que o material coletado no jornal francês sobre a Copa de 1958 confirma as especulações de Leite Lopes (1999) e Damo (2007). O olhar dos franceses oscilou entre elogios às qualidades individuais dos atletas e uma crítica ao individualismo dentro de um esporte coletivo. Os resultados das partidas influenciaram tantos os elogios quanto as críticas. E, em ambos os casos, o olhar da imprensa foi permeado por uma visão eurocêntrica, no sentido de que faltaria aos brasileiros mais razão e equilíbrio emocional, o que teria sido conquistado graças ao trabalho do médico e do psicólogo da seleção nacional. E, mesmo com a prevalência dos elogios, principalmente a partir do momento em que a seleção venceu a França, as narrativas da imprensa francesa não deixaram de lado a visão exótica do Brasil.

\section{Brasil e França na Copa do Mundo de 1998}

A Copa do Mundo de 1998 foi disputada na França entre os dias 10 de junho e 12 de julho daquele ano. Em 1998, o Brasil já havia vencido quatro Copas do Mundo (1958, 1962, 1970 e 1994), ostentava o título de atual campeão, Romário e Ronaldo (por duas vezes consecutivas) já haviam sido eleitos os melhores jogadores do mundo, e o país havia iniciado seu período de "redemocratização", com uma economia mais sólida. Ou seja, o Brasil de 1998 era diferente do Brasil de 1958, tanto em termos futebolísticos quanto socioeconômicos.

A primeira nota de destaque do material coletado apontava a seleção brasileira como favorita ao título: "No sorteio, em dezembro passado, em Marselha, o Brasil despontou claramente como favorito. De lá para cá, o jogo de forças se equilibrou, e os campeões mundiais não têm mais motivos para se sentirem

\footnotetext{
${ }^{13}$ Ver: “Le Brésil a su s’organiser défensivement, sans brider son génie offensive” (L'ÉQUIPE, 30/06/1958).
} 
os melhores" (L'ÉQUIPE, 9/6/1998). A reportagem fala sobre o corte de Romário, diz que a seleção perde muito do seu poder ofensivo e que nem Bebeto nem Edmundo teriam o carisma e a eficácia de Romário ${ }^{14}$.

No dia seguinte, uma matéria questionava: "Eles são loucos o suficiente?". E o texto dizia assim:

Quatro anos depois, o Brasil coloca seu título em jogo contra a Escócia, na abertura da competição francesa. Como nos Estados Unidos, os atletas de Zagallo se aproximam desta Copa do Mundo com uma indefinição artística. Crises, críticas, estado de ânimo e escassez de jogo, é nesse tom de samba que os atuais campeões mundiais pontuam suas ambições: eles irão encontrar esse grão de loucura que faz sua lenda? (L'ÉQUIPE, 10/06/1998, grifos nossos).

Parece evidente que, nesse início de competição, o jornal, ao apontar o Brasil como favorito, faz algumas ressalvas em relação ao suposto estilo, dizendo que a equipe estaria apostando suas fichas em um clima de samba, sem deixar claro o que isso significaria. Além disso, a narrativa diz que a lenda do futebol brasileiro estaria em sua loucura. Embora essa loucura possa ser vista como como um elogio, ela é antagônica à razão, assim como o samba nos remete ao carnaval, que seria outro momento oposto, no imaginário, à racionalidade.

Ainda no dia 10 de junho, temos uma entrevista com Ronaldo, na qual o jornalista lhe perguntava: "Você não acha que, ao contrário dos principais concorrentes, a seleção carece de um pouco de humildade?" (L'ÉQUIPE, 10/06/1998). Talvez o Brasil pudesse sentir-se confiante com quatro títulos mundiais e com Ronaldo eleito o melhor do planeta por dois anos consecutivos. De qualquer forma, a pergunta é uma forma de denúncia a uma suposta "soberba". Ronaldo responde ao jornalista dizendo que "o nosso futebol é de arte", e a nota termina com elogios: "Se, em cada treino, o público se encanta assim que ele bate na bola, Ronaldo mantém os pés no chão e nunca negligencia o seu público. Sorridente, disponível [...] Confissões de uma criança carinhosa..." (L'ÉQUIPE, 10/06/1998).

Estamos diante de um outro Brasil, bem diferente do de 1958. O de agora é reconhecido e admirado, está em alta por suas conquistas e por suas estrelas mundiais. Mesmo assim, podemos especular que a nota traz sutilmente alguns mitos construídos como o da alegria brasileira (o sorriso de Ronaldo) e o reforço do suposto estilo conhecido como futebol-arte (ênfase na resposta de Ronaldo, colocando-a como subtítulo da reportagem).

\footnotetext{
${ }^{14}$ Naquele momento, estamos em um período de globalização, com muitos jogadores brasileiros fazendo sucesso em times da Europa e com as novas tecnologias da informação trazendo as notícias em tempo real.
} 
Até a partida contra o Chile pelas quartas de final, as matérias do jornal eram positivas em relação à seleção. Dunga, o capitão do time, e que havia sido campeão em 1994, mas que simbolizava no Brasil um modelo antagônico do futebol que se convencionou chamar de futebol-arte, era elogiado por sua liderança ${ }^{15}$. Havia também elogios ao jogador Denílson, que estava na reserva. Denílson era conhecido por sua habilidade individual, e as reportagens indicavam que a imprensa francesa queria vê-lo na equipe ${ }^{16}$.

No dia seguinte ao jogo em que o Brasil venceu o Chile por 4 a 1, o jornal destacou: "Samba para o Brasil. Diante de alguns chilenos um tanto frágeis, Ronaldo (dois gols) e seus parceiros organizaram um festival no parque. Eles encontraram, sobretudo, a confiança antes das quartas de final e das coisas sérias" (L'ÉQUIPE, 28/06/1998, grifos nossos).

É interessante notar a ambiguidade da narrativa. A palavra samba, apesar do estereótipo, é um elogio aqui, assim como "festival no parque". No entanto, a matéria enfatiza que os chilenos eram frágeis e que até agora as partidas não haviam sido sérias.

Depois da vitória sobre a Dinamarca por 3 a 2, o jornal destaca o placar apertado, mas faz elogios às qualidades individuais e ao jogo coletivo de Rivaldo, jogador de meio de campo da seleção, e ao atacante Ronaldo (L'ÉQUIPE, 04/07/1998). Até o técnico Zagallo foi elogiado na reportagem, que se inicia da seguinte maneira: "Zagallo chorou... Perto do desconforto do final do jogo, esgotado pelas emoções, Mario Zagallo, paradoxalmente, nunca pareceu tão feliz. Seu Brasil brinca e se diverte, seu Brasil cativa e seduz, e ele espera por tudo isso há muito tempo" (L'ÉQUIPE, 05/07/1998, grifo nosso). A reportagem fala das críticas que Zagallo sofria da imprensa de seu país por, supostamente, ser um “técnico antiquado". Ele responde dizendo que o Brasil havia sofrido durante 20 anos por ter se inspirado em métodos europeus, distante de suas "qualidades naturais", que o Brasil tinha perdido sua identidade e que queria trazê-la de volta. Não questiono que Zagallo teria dito isso, mas chama a atenção o destaque dado pela matéria. É uma forma de voltar a falar do suposto estilo baseado em "qualidades naturais".

Antes da partida contra Holanda pelas semifinais, encontramos a seguinte manchete no jornal: “'Chuva de estrelas ou pó nos olhos?’17. Parece uma final, mas não é. Mas como duvidar, diante da chuva

\footnotetext{
${ }^{15}$ Ver L'Équipe, 11/06/1998.

${ }^{16}$ Ver L'Équipe, 22/06/1998.

17 "Pó nos olhos" é uma imagem da língua francesa que significaria "procurar deslumbrar outra pessoa com um brilho muitas vezes ilusório". Talvez faça mais sentido do que simplesmente "pó nos olhos".
} 


\section{ALCEU}

ISSN: $2175-7402$

de estrelas que cairá esta noite no Stade-Vélodrome, que Brasil-Holanda não será a celebração de um momento supremo do futebol?" (L'ÉQUIPE, 08/07/1998). Na mesma página, o jornal publica uma entrevista de Pelé, na qual ele dizia que, se fosse o técnico da seleção, colocaria Denílson na equipe.

De uma forma geral, as matérias antes dessa partida falavam em equilíbrio entre as duas equipes. Mas a entrevista que ressalta Pelé pedindo Denílson no time é significativa. Esse jogador simbolizava aquele Brasil das narrativas do início da Copa, que falavam em "grão de loucura".

Depois da vitória, nos pênaltis, contra a Holanda e a consequente classificação para a partida final, o jornal colocou na manchete: "Seis finais, uma lenda... Brasil disputará sua sexta final de Copa do Mundo no domingo. Ele estabelecerá um novo recorde, após o de vitórias (quatro no momento)" (L'ÉQUIPE, 09/07/1998). A reportagem fala da final de 1950, diz que Zagallo estava lá, uniformizado de soldado do exército. O texto diz que o Brasil perdeu seu estilo ofensivo em 1974 e 1978, mas voltou com ele em 1982 (cita Telê Santana, Junior, Cerezo, Falcão, Sócrates e Zico) e considera a seleção de 1994 um time muito prudente e que teria sido uma sombra da lenda. No último parágrafo, a matéria diz: "Menos generoso que no passado. Mas quando Roberto Carlos, Bebeto, Rivaldo, Denílson e Ronaldo são obrigados a jogarem juntos, ontem e hoje se confundem na mesma emoção. A que nasceu da arte" (L'ÉQUIPE, 09/07/1998, grifo nosso).

É curioso observar que a mitologia do futebol brasileiro aparece nessa narrativa que junta o passado com o presente, como se algo os unisse ${ }^{18}$. Aqui, este "algo" seria uma emoção que nasceria da arte $^{19}$. Passados 60 anos desde a Copa de 1938 e 40 anos desde a Copa de 1958, a narrativa da imprensa francesa continuou a ser arrastada pela mitologia e seus estereótipos, embora de forma mais sutil. No exemplo citado acima, foi uma narrativa positiva.

No entanto, a final era contra os franceses, anfitriões daquela Copa. As matérias antes da partida tendiam a apresentar um equilíbrio de forças:

A Copa do Mundo deu origem à final com a qual todos sonhavam. França-Brasil é uma história luminosa de jogos que marcaram os espíritos. De Didi a Roberto Carlos, de Garrincha a Romário, de Pelé a Ronaldo, participaram os maiores artistas brasileiros. Kopa, Fontaine, Michel, Trésor, Platini, Giresse, Papin, Blanc, Zidane, participaram da competição os maiores jogadores franceses do pós-guerra. Disputar uma partida

\footnotetext{
18 Narrativas semelhantes foram observadas em uma análise que fiz sobre a visão da imprensa argentina sobre o futebol brasileiro entre as Copas do Mundo de 1970 e 2006. Ver, mais uma vez, Helal (2007).

${ }^{19}$ Para uma discussão sobre esporte e arte, ver Gumbrecht (2007) e Melo (2005).
} 
França-Brasil, assistir a um França-Brasil, é sempre uma grande lembrança. Ainda mais na final da Copa do Mundo (L'ÉQUIPE, 10/07/1998).

A foto da reportagem é da Copa do Mundo de 1986, com o goleiro brasileiro Carlos no último gol da França durante a disputa de pênaltis. Essa é uma característica recorrente dos jornais em ocasiões semelhantes: ativar a memória de um tempo em que a França foi vitoriosa ${ }^{20}$.

No entanto, embora as narrativas tendessem a um equilíbrio de forças, havia um reconhecimento de que os atletas brasileiros eram superiores em termos técnicos. Talvez esse "reconhecimento" fosse baseado na tradição:

O Brasil não é perfeito. Enquanto os brasileiros possuem habilidade individual e velocidade suficiente para resolver qualquer problema, se seu domínio técnico é superior ao dos franceses e seu contra-ataque é formidável, por outro lado, eles não são invencíveis. Principalmente, se os fizermos duvidar (L'ÉQUIPE, 11/07/1998).

Não está claro o que significa "se os fizermos duvidar". A nota fala do toque de bola do Brasil e sua capacidade de acelerar o jogo, mas aponta a dupla de zaga, com Aldair e Junior Baiano, como sendo frágil no jogo aéreo. Toda a reportagem tenta explicar como a França deve jogar para vencer o Brasil.

Após a vitória da França por 3 a 0, o que prevaleceu no material analisado foi a exaltação da vitória dos donos da casa. A capa de 13 de julho era: "Para a eternidade. A França venceu a 16a Copa do Mundo de futebol na noite passada vencendo o Brasil (3-0) com dois gols de Zinedine Zidane e um de Emannuel Petit. Sucesso histórico que faz do Blues de Aimé Jacquet os últimos campeões mundiais do século" (L'ÉQUIPE, 13/06/1998).

Nessa mesma edição, havia uma reivindicação sobre a entrada de Denílson na equipe: "Denílson, mas tarde demais! Os jogadores brasileiros nunca fizeram jus à sua reputação na noite passada. Apenas Denílson, que entrou no segundo tempo, conseguiu subir ao nível de uma final" (L'ÉQUIPE, 13/07/1998). Denílson, nas narrativas do jornal, seria um exemplo do "estilo "de jogo brasileiro. Denílson era visto como possuidor de muitas habilidades, mas muito individualista. Não podemos afirmar, porém, se estamos aqui diante da ambivalência observada por Damo (2007) em sua análise sobre a Copa do Mundo de 1938.

Dois dias depois da final, uma nota lamentava a convulsão de Ronaldo: "Ainda não sabemos por que Ronaldo convulsionou. Talvez um ataque epiléptico. Só sabemos que ele foi levado às pressas para a

\footnotetext{
${ }^{20}$ Isso foi observado, por exemplo, em uma análise que fiz junto com Álvaro do Cabo sobre as narrativas da imprensa uruguaia sobre a partida entre Brasil e Uruguai na Copa do Mundo de 1970. Ver Cabo e Helal (2010).
} 
clínica de Lilás cinco horas antes da final. Mas uma coisa é certa: patrocinadores, pressão e sobrecarga de trabalho estão matando Ronaldo" (L'ÉQUIPE, 14/07/1998).

\section{Considerações Finais}

Durante meu estágio na França, Patrick Mignon, que supervisionou a pesquisa, sugeriu que eu lesse um livro que, segundo ele, refletia a opinião que a imprensa francesa e os franceses tinham do futebol brasileiro. O livro do escritor e jornalista Olivier Guez é intitulado, no original em francês, Éloge de L'Esquive, o que seria algo como "elogio do drible". Na quarta capa do livro, lemos:

O drible não nasceu por acaso no Brasil. Os primeiros jogadores negros começaram a driblar para evitarem o contato com os zagueiros brancos e não serem golpeados em campo e ao final dos jogos. Desenvolveu-se em praias e terrenos baldios, com uma bola de meias ou uma pequena bola de borracha. É um movimento de quadril, parecido com o dos sambistas e dos lutadores de capoeira, lúdico, acrobático, marca registrada dos maiores solistas. "Ousadia e alegria" - os recursos de Neymar. O futebol é sublime, pueril, e, se desperta tantas emoções, deve-o ao drible brasileiro: uma arte livre, alegre, apaixonada....

Notemos que Guez está encantado com o futebol brasileiro. Porém, seu encanto se concentra nas mitologias construídas dentro e fora do Brasil, como um país "tropicalista" ${ }^{21}$. Segundo Guez, o drible, típico de um esporte como o futebol, teria nascido no Brasil, e não na Inglaterra, onde o futebol foi, de fato, gerado. Os inventores desse artifício do futebol teriam sido os negros brasileiros para evitar serem derrotados pelos brancos. Além disso, o drible teria se desenvolvido nas praias e em terrenos baldios, e seus movimentos seriam correlacionados aos dos sambistas e dos capoeiristas ${ }^{22}$. Tudo isso junto resultaria em um futebol alegre, ousado e emocionante. O livro é uma narrativa romântica e mitológica do futebol brasileiro ${ }^{23}$. Apesar do tom elogioso, o livro segue uma linha de raciocínio semelhante à encontrada no material da imprensa francesa sobre o futebol brasileiro, principalmente nas narrativas elogiosas. Ou seja, sua base de elogio, louvor e encantamento está centrada na "natureza" dos habitantes do país.

\footnotetext{
21 Para uma explicação do significado de país "tropicalista" e uma comparação entre modos de representar o Brasil e a Argentina, ver Ribeiro (2002).

22 Esse tipo de raciocínio, se esticado, pode levar a uma apologia da pobreza, no sentido de que os melhores jogadores seriam sempre oriundos de uma infância pobre. Ver, a respeito, Lovisolo e Helal (2008). Ver também Helal (2011) para uma discussão sobre os mitos do futebol brasileiro.

${ }^{23} \mathrm{O}$ livro é escrito em tom de ensaio e é tragado pela construção simbólica do futebol brasileiro. As convergências com o livro $O$ Negro no Futebol Brasileiro de Mario Filho são muitas.
} 
Em um estudo sobre o olhar dos franceses sobre o Brasil entre os séculos XVI e XVIII, Carmen Lucia Palazzo (2010, p. 180) nos mostra como “o fascínio pela natureza exuberante, pela abundância, pelo tamanho da floresta e dos animais também reacendeu a memória dos mitos e utopias como a Cocanha, país de abundância e liberdade"24. Em sua conclusão, Palazzo mostra como a visão dos franceses passou de uma narrativa do mítico e do fantástico para o exótico, a partir do século XVIII. Pena que sua obra não analise o olhar dos franceses nos séculos seguintes. Mas suspeitamos que a questão do exótico, tanto positiva quanto negativamente, continuou a prevalecer nos séculos XIX e XX e continua até hoje, embora de forma mais sutil. Ella Shobat e Robert Stam (2006), em um estudo sobre a imagem eurocêntrica no cinema, e tangencialmente na literatura, tendem a convergir com essa suspeita. Maranúbia Barbosa (2006), em uma análise sobre os festejos referentes ao Ano do Brasil na França, em 2005, mostra como os franceses construíram uma imagem distorcida do Brasil em seu imaginário. Para os franceses, o Brasil seria "um país de balangandãs, muita festa, gente alegre, sol o ano inteiro, mulatas bronzeadas, carnaval e futebol" (BARBOSA, 2006, p. 69). Isabel Travancas (2002), em uma análise sobre a cobertura da imprensa francesa sobre o movimento "Diretas Já", ocorrido no Brasil em 1984, demonstra como os jornais Le Monde e Libération se utilizaram de estereótipos de "exotismo" em suas narrativas.

Neste artigo fiz uma análise preliminar das reportagens do jornal L'Équipe sobre a seleção brasileira de futebol nas Copas de 1958 e 1998. Compartilho a opinião de que sempre que vamos falar de um país ou de um grupo social formado de milhões de indivíduos, a tendência é homogeneizar esse grupo e, quase inevitavelmente, usar estereótipos para analisá-lo. Esta seria uma armadilha sociológica difícil de desbloquear. Além disso, é difícil saber o quanto dessa visão homogeneizada e carregada de estereótipos vem do próprio grupo analisado ou apenas da responsabilidade do analista. Desconfio que, com frequência, e principalmente no caso da visão francesa sobre o Brasil, sejam ambos os movimentos.

A opinião de fora sempre teve muita importância no pensamento social brasileiro ${ }^{25}$, e a França teve uma influência enorme neste processo. É verdade que há registros de resistência, sendo a mais conhecida a Semana de Arte Moderna de 1922, que reuniu um grupo de intelectuais e artistas que queriam romper com a tradição acadêmica e com as influências da cultura europeia, principalmente francesa, e, assim,

\footnotetext{
${ }^{24}$ Sobre Cocanha, ver Hilário Franco Júnior (1998).

${ }^{25}$ Ver, a esse respeito, em termos da influência da compreensão política do Brasil, Souza (2017). Ver também Herschmann e Lerner (1993) e Carvalho (2014) sobre a influência da Europa, especialmente da França, no Rio de Janeiro no início do século XX.
} 
inspirar-se no que seriam as raízes culturais brasileiras ${ }^{26}$. No entanto, o olhar de fora parece ter sido preponderante para o sucesso das narrativas de Gilberto Freyre e Mario Filho, conforme já mencionado.

$\mathrm{Na}$ já citada crônica de Freyre, "Foot-ball Mulato", observamos que seu relato fala de um ser híbrido que seria superior aos demais: o mulato 27 :

Acaba de se definir de maneira inconfundível um estilo brasileiro de foot-ball; e esse estilo é mais uma expressão do nosso mulatismo ágil em assimilar, dominar, amolecer em dança, em curvas ou em músicas técnicas européias ou norte-americanas mais angulosas para o nosso gosto: sejam elas de jogo ou de arquitetura. Porque é um mulatismo, o nosso - psicologicamente, ser brasileiro é ser mulato - inimigo do formalismo apolíneo [...] e dionisíaco a seu jeito - o grande jeitão mulato. Inimigo do formalismo apolíneo e amigo das variações; deliciando-se em manhas moleironas, mineiras a que se sucedem surpresas de agilidade.

É importante destacar que, antes de Freyre, esse processo narrativo, baseado em qualidades naturais, já era encontrado em outras crônicas, como a de José Lins do Rego, escrita logo após a conquista brasileira da Copa Rio Branco, em Montevidéu, contra os uruguaios, naquela ocasião já bicampeões olímpicos (1924-1928) e mundiais (1930):

Os rapazes que venceram em Montevidéu eram um retrato de uma democracia social, onde Paulinho, filho de família importante, se uniu ao negro Leônidas, ao mulato Oscarino, ao branco Martim. Tudo feito à boa moda brasileira, na mais simpática improvisação. (...) eu acredito no Brasil, nas qualidades eugênicas dos nossos mestiços, na energia e na inteligência dos homens que a terra brasileira forjou com sangues diversos, dando-Ihes uma originalidade que será um dia espanto do mundo (REGO, 1943, p. 7-8, grifo nosso).

Há indícios de que havia uma tendência da imprensa brasileira de se concentrar mais nos elogios da imprensa francesa ao futebol jogado pela seleção brasileira do que nas críticas. Leite Lopes (1999, p. 67), por exemplo, ao analisar esse período, nos diz que:

De fato, o reconhecimento internacional desse novo estilo é mais matizado, mais crítico do que o noticiado pela imprensa brasileira, que em vez disso enfatiza elogios e boas notícias. As matérias dos jornalistas do L'Auto deixam perceber um certo encantamento por este estilo inovador, mas também um certo aborrecimento, até desconfiança perante o novo. Percebe-se inclusive uma condenação de cunho racialista, que presumivelmente se alimenta das mesmas fontes do racismo de parte significativa da sociedade brasileira.

\footnotetext{
${ }^{26}$ Apesar de que o modernismo brasileiro foi um movimento artístico e cultural heterogêneo, com nomes como o do integralista Plínio Salgado e do poeta vanguardista Oswald de Andrade. O que unia nomes tão diferentes era a pergunta "o que é o Brasil?". A busca pela renovação e as respostas dadas a essa questão moveram a produção de seus principais agitadores culturais, como Mario de Andrade e Oswald de Andrade. Ambos visaram redescobrir o Brasil a partir da valorização da cultura popular e de uma produção artística livre da influência estrangeira. Da busca por uma identidade própria, surgiu um dos dilemas do movimento, que consistia no fato de que a valorização daquilo que era considerado nacional surgia a partir da influência direta das vanguardas europeias. Ver Amaral (1970), Ruffinelli e Rocha (2011) e Vianna (1995). Sou grato, mais uma vez, a Leda Costa.

${ }^{27}$ Sabemos da conotação preconceituosa do termo hoje em dia. O artigo é de 1938.
} 
Soares e Lovisolo (2011, p. 33) apontam a existência, desde o início do século XX, de uma "tensão entre os ideais civilizadores e a afirmação da autenticidade cultural", ainda que na definição do que seria o estilo brasileiro "se enfatize mais as habilidades individuais, o que torna a disciplina e o jogo em equipe secundários" (p. 35). Nesse sentido, os autores tendem a convergir com o que Leite Lopes afirma acima.

O que estou tratando de formular como hipótese aqui é que, nessa visão eurocêntrica dos franceses sobre o Brasil, o próprio país teria sua cota de responsabilidade, como se o olhar de fora fosse uma via de mão dupla. Rentero e Terra (2016) também convergem com essa hipótese em uma análise sobre as narrativas do L'Équipe sobre o Brasil entre 2010 e 2014. Após demonstrarem a recorrência dos estereótipos naturalizados para falar do Brasil, eles concluem:

mais do que despir-se de uma máscara para que possamos nos enxergar como realmente somos, é perceber que, com ou sem máscara, fomos nós que permitimos essa visão do mundo sobre nós mesmos. Consentimos calados, e até de certa forma orgulhosos quando nos convêm (RENTERO; TERRA, 2016, p. 397).

No início deste artigo, vimos como as análises de Leite Lopes (1999) e Damo (2007) sobre a Copa de 1938 apontavam para uma ambivalência nas narrativas francesas, que ora elogiavam as habilidades dos atletas brasileiros, ora criticavam uma suposta falta de jogo coletivo, de racionalidade.

Em nossa análise do material coletado na Copa de 1958, 20 anos após a Copa de 1938, essa ambivalência apareceu com intensidade. Foi interessante notar que o mesmo jornalista, Gabriel Hanot, das crônicas de 1938, continuou com raciocínio semelhante. Tanto para elogiar quanto para criticar, a principal justificativa estava centrada na natureza dos indivíduos dos trópicos ${ }^{28}$. Tanto Freyre, em seu artigo "Football Mulato", de 1938, quanto Filho, em suas crônicas esportivas e em seu livro O Negro no Futebol Brasileiro, elogiam o futebol brasileiro baseado na miscigenação do país, que teria gerado um ser híbrido superior. Embora as narrativas desses autores sejam voltadas principalmente para o elogio, sem ambivalência, a base continua sendo as características "naturais" dos indivíduos, especialmente dos mestiços do país.

\footnotetext{
${ }^{28}$ Cabe aqui uma lembrança ao pensamento do barão Pierre de Coubertin, criador dos Jogos Olímpicos da era moderna. Fausto Amaro (2018), em sua tese de Doutorado, nos informa sobre um folheto, intitulado "O que é o Olimpismo?", escrito por Coubertin em 1917 e que circulou pela imprensa carioca, em uma versão traduzida, em 1921. Coubertin (2015, p. 742) compartilha sua visão sobre as causas de certo subdesenvolvimento do esporte no continente sul-americano. Nas palavras dele: "O seu continente, vasto, belo, banhado pelo sol e repleto de todas as riquezas da natureza, adormeceu-lhes, meus caros amigos".
} 


\section{ALCEU}

Em 1998, após 60 anos da Copa de 1938 e 40 do Mundial de 1958, com a Seleção Brasileira detentora do único título (na época) de tetracampeã, num momento de globalização do mundo e em que o país estava passando por uma relativa estabilidade econômica, reconstruindo seu sistema democrático, e seus melhores atletas logravam sucesso na Europa, as narrativas continuaram carregadas de uma visão eurocêntrica, embora de forma menos intensa e mais sutil. De qualquer forma, isso foi um pouco surpreendente, já que não esperava encontrar narrativas desse tipo nessa época.

Antes de finalizar, gostaria de propor alguns questionamentos. Por ocasião de minha pesquisa de pós-doutorado em Buenos Aires, já mencionada neste artigo, observei que as narrativas da imprensa argentina sobre a seleção brasileira trabalhavam com alguns estereótipos semelhantes aos que encontrei na análise do jornal L'Équipe apresentada aqui. Alegria e individualismo eram atributos muito citados no que ficou conhecido como "jogo bonito" (escrito em português pelos argentinos). O individualismo, embora às vezes visto como negativo, não parecia ser causado por questionamentos sobre a natureza dos indivíduos, a despeito das narrativas de que o suposto "jogo bonito" seria uma das características de jogadores negros e mestiços do Brasil. A ênfase recaía mais em uma questão cultural. De qualquer forma, é interessante notar as semelhanças entre as narrativas argentina e francesa sobre o futebol brasileiro. Desse modo, questiono se não haveria algo no futebol brasileiro capaz de produzir essas narrativas. Ou seja, embora esses estereótipos sejam construídos socialmente, eles são eficazes interna e externamente.

É importante destacar que a formação simbólica do futebol argentino é muito parecida com a do Brasil. Brasil e Argentina "construíram" para si uma imagem de um "estilo de jogo" baseado no drible (gambeta na Argentina) e na improvisação, em contraposição à rigidez dos esquemas táticos que seriam típicos do futebol europeu, de forma generalizada, no caso brasileiro, e futebol inglês, no caso argentino. Porém a tendência é que os argentinos tenham uma autoimagem de nostalgia, em oposição à alegria do Brasil. Além disso, parece que esta imagem do nostálgico e, às vezes, soberbo argentino também faz sucesso fora da Argentina. Assim, temos os mitos construídos e sua eficácia simbólica, frequentemente materializada no cotidiano dos cidadãos dos países ${ }^{29}$.

É interessante notar que a bandeira do Brasil leva as palavras ordem e progresso. A expressão é o lema político do positivismo, formulado pelo filósofo francês Auguste Comte. Portanto, podemos especular

\footnotetext{
${ }^{29}$ Apesar de que os heróis argentinos teriam uma tendência mais "dionisíaca" e os heróis brasileiros, uma tendência mais "apolínea" (utilizando os termos de Freyre em "Foot-Ball Mulato"). Ver, a esse respeito, Helal e Lovisolo (2009).
} 
aqui, mais uma vez, sobre a influência do pensamento francês no Brasil e o desejo oficial do país de ser visto como ordeiro e progressista. Por outro lado, o Brasil informal constrói para si uma imagem mais dionisíaca, de alegria, diversão, improvisação, o famoso dito "País do Carnaval" (e do futebol também). Os brasileiros seriam atormentados por essa dicotomia? Ou pelo menos a elite e a imprensa brasileira? Isso poderia contribuir para a resistência dos franceses em romper com a visão "eurocêntrica" do país? Até quando o Brasil será visto como um país exótico, tanto para elogiar quanto para criticar sua cultura?

Será que a resistência francesa em romper com esse olhar eurocêntrico, como colocam Shobat e Stam (2006) e, de outra maneira, Barbosa (2006), Travancas (2002) e Rentero e Terra (2016), tenha a ver com o fato de os brasileiros continuarem a levar em conta a visão que vem de fora e também gostarem de passar essa imagem para o estrangeiro? Os brasileiros também não seriam responsáveis por esse olhar de fora sobre eles? E, se a resposta for positiva, o que isso significa?

Ronaldo Helal

ORCID: https://orcid.org/0000-0002-7688-3925 Universidade do Estado do Rio de Janeiro, Departamento de Comunicação, Rio de Janeiro (RJ), Brasil. Doutor em Sociologia pela New York University E-mail: rhelal@globo.com

Recebido em: 12 de março de 2021.

Aprovado em: 27 de março de 2021.

\section{Referências:}

AMARAL, Aracy. Blaise Cendrars no Brasil e os modernistas. São Paulo: Martins, 1970.

AMARO, Fausto. Os jogos olímpicos na capital da República: narrativas da imprensa e campo esportivo no Rio de Janeiro (1890-1935). 2018. 415 f. Tese (Doutorado em Comunicação) - Faculdade de Comunicação Social, Universidade do Estado do Rio de Janeiro, Rio de Janeiro, Brasil, 2018.

ARAÚJO, Ricardo Benzaquen de. Guerra e Paz: Casa-Grande \& Senzala e a Obra de Gilberto Freyre nos anos 30. São Paulo: Editora 34, 1994. 
BARBOSA, Maranúbia. O Brasil é um país de "balangandãs" no imaginário francês. Discursos Fotográficos, Londrina, v. 2, n. 2, p. 62-92, 2006.

BARRETO, Túlio V. Gilberto Freyre e o Futebol-Arte. Revista USP, São Paulo, n. 62, p. 233-238, junho/agosto 2004.

CABO, Alvaro; HELAL, Ronaldo. El Mundial de 1930: un análisis de la prensa uruguaya acerca del evento. Revista Latinoamericana de Ciencias de la Comunicación, v. 12, p. 126-136, 2010.

CANDIDO, Antonio. O romantismo no Brasil. São Paulo: Humanitas-FFLCH, 2002.

CARVALHO. José Murilo. Os bestializados: o Rio de Janeiro e a república que não foi. São Paulo: Companhia das Letras, 2014.

CASTRO, Ruy. Estrela solitária: um brasileiro chamado Garrincha. São Paulo: Companhia das Letras, 1995.

COUBERTIN, Pierre. Pierre de Coubertin: Olimpismo - Seleção de textos (Norbert Muller e Nelson Schneider Todt [Editores]). Porto Alegre: ediPUCRS, 2015.

DRUMOND, Maurício. Estado Novo e Esporte: a política e o esporte em Getulio Vargas e Oliveira Salazar. Rio de Janeiro: Sete letras, 2014.

DAMO, Arlei. Artistas primitivos: os brasileiros na Copa de 38 segundo os jornais franceses. In: Simpósio Nacional de História - ANPUH XXIV, 2007. Anais... São Leopoldo: Unisinos, 2007.

FRANCO JÚNIOR, Hilário. Cocanha: a História de um País Imaginário. Rio de Janeiro, Companhia das Letras, 1998.

FILHO, Mario. Copa do Rio Branco, 32. Rio de Janeiro: Irmãos Pongetti Editores, 1943.

O Negro no Futebol Brasileiro. Rio de Janeiro: Editora Civilização Brasileira, 1964.

FREYRE, Gilberto. Foot-Ball Mulato. Diário de Pernambuco, 17 de junho de 1938.

. Casa Grande e Senzala. Rio de Janeiro: José Olympio Editora, 1987.

GUEZ, Olivier. Éloge de l’esquive. Paris, Bernard Grasset, 2014.

GUMBRECHT. Hans. Elogio da Beleza Atlética. São Paulo: Companhia das Letras, 2007

HELAL, Ronaldo. Mitos e Verdades do Futebol (que nos ajudam a entender quem somos). Insight Inteligência (Rio de Janeiro), v. 52, p. 68-81, 2011.

- "Jogo Bonito" y "Fútbol Criollo": la relación futbolística Brasil-Argentina en los medios de comunicación. In: GRIMNSON, Alejandro (Org.) Pasiones Nacionales: política y cultura en Brasil y Argentina. Buenos Aires: Edhasa, 2007, p. 349-385. 
; SOARES, Antonio Jorge G.; LOVISOLO, Hugo. A Invenção do País do Futebol: mídia, raça e idolatria. Rio de Janeiro: Mauad, 2001.

; LOVISOLO, Hugo. Pelé e Maradona: núcleos da retórica jornalística. Revista Brasileira de Futebol, v. 2, p. 20-26, 2009.

HERSCHMANN, Micael; LERNER, Kátia. Lance de Sorte: o futebol e o jogo do bicho na Belle Époque Carioca. Rio de Janeiro: Diadorim, 1993.

LEITE LOPES, José Sérgio. Les origines du jeu à la brésilienne. In: HÉLAL, Henri; MIGNON, Patrick (Orgs.) Football; Jeu et Société, Les Cahiers de I’INSEP, n. 25, p. 65-84, 1999.

. O estilo brasileiro de futebol, seus dilemas e seus intérpretes. In: GARGANTA Julio; OLIVEIRA, José; MURAD, Mauricio (Orgs.) Futebol de Muitas Cores e Sabores. Porto: Ed. Universidade do Porto, 2004, p. 21-30.

LOVISOLO, Hugo; HELAL, Ronaldo. Jornalismo Esportivo, Romantismo e Apologia da pobreza. Revista Polêmica, v. 7, p. 157-162, 2008.

MARANHÃO, Tiago. "Apolíneos e dionisíacos" - o papel do futebol no pensamento de Gilberto Freyre a respeito do "povo brasileiro". Análise Social, Lisboa, v. 179, p. 435-450, 2006.

MELO, Victor. O esporte como uma forma de arte: diálogos entre (duas?) linguagens. Porto Alegre, Movimento, 2005, p.111-130.

MOSTARO, Filipe. Garrincha x Pelé: a influência da mídia na carreira de um jogador. Juiz de Fora: Juizforana, 2012.

PALAZZO, Carmem Lícia. Entre mitos, utopias e razão: os olhares franceses sobre o Brasil (séculos XVI a XVII). Porto Alegre: EdiUCRS, 2009.

REGO, José Lins do. Prefácio. In: FILHO, Mario. Copa do Rio Branco, 32. Rio de Janeiro: Irmãos Pongetti Editores, 1943, p. 7-8.

RIBEIRO, Gustavo Lins. Tropicalismo e Europeísmo: modos de representar o Brasil e Argentina. In: FRIGERIO, Alejandro; RIBEIRO, Gustavo Lins. Argentinos e Brasileiros: encontros, imagens e estereótipos. Petrópolis, Vozes, 2002.

RENTERO, Matheus Moraes; TERRA, Vinícius Demarchi Silva. A Identidade Brasileira em jogo na imprensa francesa. São Paulo: Ludens, 2016.

RODRIGUES, Nina. As raças humanas e a responsabilidade penal no Brasil. Rio de Janeiro: Centro Edelstein de Pesquisa Social, 2011.

RODRIGUES, José Carlos. Antropologia e Comunicação. Princípios Radicais. Rio de Janeiro: Espaço e Tempo, 1989. 
RUFFINELLI, Jorge; ROCHA, João Cezar de Castro. Antropofagia hoje? Oswald de Andrade em Cena. São Paulo: É Realizações, 2011

SHOBAT, Ella; STAM, Robert. Crítica da imagem eurocêntrica. São Paulo: Cosac Naify, 2006.

SOARES, Antonio Jorge G; LOVISOLO, Hugo. Futebol: a construção histórica do estilo nacional. In: HELAL, Ronaldo; LOVISOLO, Hugo; SOARES, Antonio Jorge G. (orgs.) Futebol, jornalismo e ciências sociais: interações. Rio de Janeiro: Eduerj, 2011, p. 33-51.

SOUZA, Denaldo Alchorne. O Brasil entra em campo: construções e reconstruções da identidade nacional (1930-1947). São Paulo: Annablume, 2008.

SOUZA, Jessé. A elite do Atraso: da escravidão à lava jato. Rio de Janeiro: Leya, 2017.

TRAVANCAS, Isabel. Samba, futebol e democracia? A cobertura do movimento "Diretas Já" pela imprensa francesa. Revista Contracampo, Niterói, n. 6, p. 83-98, 2002.

VIANA, Oliveira. Populações Meridionais do Brasil. Rio de Janeiro: Paz e terra, 1974.

VIANNA, Hermano. O mistério do samba. Rio de Janeiro: Jorge Zahar Editor, 1995.

\section{Resumo}

O artigo apresenta uma análise das narrativas do jornal L'Équipe sobre o futebol brasileiro nas Copas de 1958 e 1998. Parte-se da hipótese de que foi a partir da atuação da seleção brasileira na Copa do Mundo da França, em 1938, e do "olhar" da imprensa francesa sobre o futebol brasileiro que as ideias do antropólogo Gilberto Freyre e do jornalista Mario Filho, de que o futebol brasileiro seria mais artístico, se consolidaram no país. Pressupõe-se que os franceses, em geral, olhavam o Brasil como um país exótico, com todos os estereótipos "positivos" e "negativos" que permeiam essa visão. Esses estereótipos continuariam aparecendo na imprensa francesa nas Copas de 1958 e $1998 ?$

Palavras-chave: Futebol. Jornalismo. L’Équipe. Narrativas. Identidade nacional.

\section{Abstract}

The article presents an analysis of L'Équipe newspaper narratives about Brazilian soccer at the 1958 and 1998 World Cups. We started from the hypothesis that it was from the performance of the Brazilian team at the World Cup in France, in 1938, and from the "look" of the French press on Brazilian soccer that the ideas of anthropologist Gilberto Freyre and journalist Mario Filho, that 
Brazilian soccer would be more artistic, consolidated in the country. It is assumed that the French, in general, looked at Brazil as an exotic country, with all the "positive" and "negative" stereotypes that permeate this view. Would these stereotypes continue to appear in the French press at the 1958 and 1998 Cups?

Keywords: Brazilian soccer. Journalism. L’Équipe. Narratives. National identity.

\section{Resumen}

El artículo tiene como objetivo presentar un análisis de las narrativas del periódico L'Équipe sobre el fútbol brasileño en los Mundiales de 1958 y 1998. Son dos Mundiales emblemáticos. En 1958, Brasil fue campeón por primera vez y derrotó a la selección francesa en las semifinales por 5 a 2. En 1998, Brasil y Francia llegaron a la final, y Francia venció a Brasil por 3 a 0, en la Copa del Mundo en la que fue anfitriana. Partimos de la hipótesis de que fue de la actuación de la selección brasileña en el Mundial de Francia, en 1938, y de la "mirada" de la prensa francesa sobre el fútbol brasileño que las ideas del antropólogo Gilberto Freyre y del periodista Mario Filho, que el fútbol brasileño sería más artístico, se consolidaron en el país. Continuando con esta hipótesis, se asume que los franceses, en general, miraron a Brasil como un país exótico, con todos los estereotipos "positivos" y "negativos" que impregnan esta visión. ¿Seguirán apareciendo estos estereotipos en la prensa francesa en los Mundiales de 1958 y 1998 ?

Palabras clave: Fútbol brasileño. Periodismo. L'Équipe. Narrativas. Identidad nacional.

Este artigo é publicado em acesso aberto (Open Access) sob a licença Creative Commons Attribution Non-Commercial (CC-BY-NC 4.0), que permite que outros remixem, adaptem e criem a partir do seu trabalho para fins não comerciais, e embora os novos trabalhos tenham de lhe atribuir o devido crédito e não possam ser usados para fins comerciais, os usuários não têm de licenciar esses trabalhos derivados sob os mesmos termos. 